ISSN : 2354-5852

e-ISSN : 2579-5783

\title{
PENGARUH PEMBERIAN AIR REBUSAN MAHKOTA DEWA (Phaleria macrocarpa (Scheff) Boerl) TERHADAP KADAR ASAM URAT DARAH PADA WANITA MENOPAUSE
}

\author{
Didien Ika $S^{I}$., Erni Dwi W. ${ }^{I}$, Ari Kusmiwiyati ${ }^{I}$

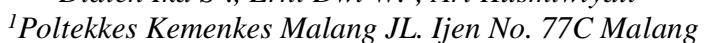 \\ Email:diana.qonitat@gmail.com
}

\begin{abstract}
Water decoction of Mahkota Dewa (Phaleria macrocarpa (Scheff) Boerl)'s effect on Blood Uric Acid Levels in Menopaused Women
\end{abstract}

Uric acid is the final result of purine metabolism in the body, which excreted through urine. In gout conditions, there is uric acid crystals deposit in joints. In the women's uric acid levels did not increase until menopause because estrogen helps to increase spending uric acid in the kidneys by reducing the amount of uric acid reabsorption. Phaleria macrocarpa (Scheff) Boerl is a plant that has medicinal properties to treat gout because Phaleria macrocarpa (Scheff) Boerl contains flavonoids that can lower uric acid by the mechanism of resistance to the activity of xanthine oxidase on purine bases so that it will reduce production of uric acid. The purpose of this study was to determine the effect of giving Phaleria macrocarpa (Scheff) Boerl's decoction water on uric acid's level in postmenopausal women in RW 01 Kelurahan Kebonsari Sukun Malang. This research is Pre Experiment with one group pre-post test design. Using 24 postmenopausal women who suffer from uric acid with total sampling technique. Test data analysis using the Wilcoxon Signed Rank Test on the significant level $\alpha=$ 0.05. The results showed $87.5 \%$ of respondents had decreased levels of uric acid and $12.5 \%$ of respondents did not experience changes in uric acid's level or are likely to remain. Results of analysis of test data with Wilcoxon Signed Rank Test $Z_{\text {hitung }}$ obtained (-4.02) < $Z_{\text {Table }}(1,96)$. It's means there is influence of Phaleria macrocarpa (Scheff) Boerl's decoction water to reduction of uric acid levels in postmenopausal women. Referring to these results it is expected that Phaleria macrocarpa (Scheff) Boerl can be used as therapy in the treatment of gout.

Keywords : Water decoction of Mahkota Dewa, Levels of Uric Acid, Female Menopause

\section{Pendahuluan}

Menopause adalah perubahan yang normal terjadi pada kehidupan seorang wanita ketika periode menstruasinya berhenti. Seorang wania sudah mencapai menopause apabila dia tidak mendapatkan menstruasi selama 12 bulan secara berurutan, dan tidak ada penyebab lain untuk perubahan yang terjadi selama menopause, yang umumnya terjadi pada usia 45-55 tahun (Depkes RI; 2005). Sejak usia 40 tahun, ovarium menjadi kurang responsif terhadap hormone pituitary yang mengendalikannya, mengurangi jumlah hormone ovarium yang dihasilkan, dan mengubah jumlah estrogen dan progesterone yang dihasilkan. Penurunan dan bahkan kehilangan sekresi estrogen dan progesterone menyebabkan perubahan endokrin yang terjadi selama masa klimakterium dan pasca menopause. Jumlah folikel yang mengalami atresia makin meningkat, sampai suatu ketika tidak tersedia lagi folikel yang cukup, produksi estrogen pun berkurang dan tidak terjadi haid lagi yang berakhir dengan terjadi menopause (Purwoastuti, Th. Endang; 2008).

Berdasarkan data Biro Pusat Statistik (BPS) untuk proyeksi penduduk 2010, di Indonesia diperkirakan ada 5.846.000 perempuan yang memasuki masa menopause yaitu 2,5\% dari penduduk Indonesia. Pada wanita menopause rentan terhadap berbagai penyakit. Salah satu akibat dari penurunan estrogen pada menopause adalah maningkatnya penumpukan asam urat dalam tubuh. Menurut Hembing Wijayakusuma (2006), asam urat merupakan sebutan orang awam untuk rematik pirai (gout artritis). Selain osteoartritis, asam urat merupakan jenis rematik artikuler terbanyak yang menyerang penduduk di Indonesia. Penyakit ini merupakan gangguan metabolik karena asam urat (uric acid) menumpuk dalam jaringan tubuh. Uric acid adalah zat hasil akhir metabolisme purin dalam tubuh, yang kemudian dibuang melalui urin. Pada kondisi gout, terdapat timbunan atau defosit kristal asam urat di dalam persendian. 
Pada perempuan kadar asam urat tidak meningkat sampai setelah menopause karena hormon estrogen akan membantu meningkatkan pengeluaran asam urat dalam ginjal dengan mengurangi jumlah reabsorbsi asam uratnya. Sehingga jumlah asam urat yang diekskresikan akan meningkat dari pada jumlah asam urat yang direabsorbsi. Jadi asam urat akan dibantu pengeluarannya oleh hormone estrogen melalui urine. Karena setelah menopause, wanita tidak lagi memiliki hormon estrogen maka kadar asam uratnya akan meningkat seperti pada pria. Di Indonesia, Asam urat terjadi pada usia yang lebih muda, pada wanita kadar asam urat umumnya rendah dan meningkat setelah usia menopause. Prevalensi asam urat di Bandungan, Jawa Tengah, prevalensi pada kelompok usia 15-45 tahun sebesar 0,8\%; meliputi wanita $0,05 \%$. Di Minahasa (2003), proporsi kejadian asam urat sebesar $29,2 \%$ dan pada etnik tertentu di Ujung Pandang sekitar $50 \%$ penderita rata-rata telah menderita gout 6,5 tahun atau lebih setelah keadaan menjadi lebih parah (http://www.jurnalmedika.com).

Setelah dilakukan studi pendahuluan pada tanggal 28 Juni 2011 di RW 01 Kelurahan Kebonsari Kecamatan Sukun Kota Malang, diketahui bahwa terdapat 37 wanita yang sudah mengalami menopause dan dari wanita menopause tersebut yang menderita asam urat sebanyak 24 orang.

Kejadian penyakit asam urat pada wanita menopause menjadi suatu hal yang mengganggu karena setiap wanita menopause ingin dirinya tetap dalam keadaan sehat tanpa adanya penyakit seperti asam urat. Untuk itu mereka melakukan berbagai upaya untuk mengatasi penyakit tersebut, salah satunya dengan cara mengkonsumsi ramuan herbal. Hal ini juga didukung oleh penelitian dan pengembangan tanaman obat yang saat ini telah berkembang pesat, terutama pada segi farmakologi maupun fitokimianya. Penelitian ini digunakan untuk mencari tanaman yang berpotensi sebagai tanaman obat. Salah satu tanaman yang dikembangkan adalah mahkota dewa.

Beberapa hasil penelitian yang telah dilakukan menunjukkan bahwa tanaman mahkota dewa mempunyai potensi sebagai antiinflamasi, antihistamin, dan memiliki efek penghambatan pada sel kanker leukemia THP-1. Daging buah mahkota dewa juga mempunyai efek hipoglikemik. Hasil uji keamanan menunjukkan perasan daging buah segar mahkota dewa tidak mempengaruhi fungsi ginjal pada tikus putih jantan dan betina pada pemakaian jangka panjang. Menurut hasil penelitian Endah Hasturani dari Fakultas Farmasi, Universitas Sanata Dharma pada 2003, perasan daging buah mahkota dewa telah terbukti efektif menurunkan kadar asam urat pada ayam jantan jenis Lohman Brown dengan dosis 13,16g/kgBB (Majalah Flona Edisi 27/II-mei 2005).

Berdasarkan penelitian Arini (2003), diketahui bahwa daging buah mahkota dewa mengandung flavonoid. Ekstrak etanol 70\% daging buah mahkota dewa mempunyai kadar relatif flavonoid yang paling besar $(45,734 \mu \mathrm{g} / \mathrm{mg})$. Keefektifan mahkota dewa untuk mengobati asam urat diduga didasarkan pada kandungan flavonoidnya. Kemampuan senyawa tersebut dalam menurunkan asam urat adalah dengan mekanisme hambatan terhadap aktivitas xantin oksidase pada basa purin sehingga akan menurunkan produksi asam urat. Selain itu, tanaman tersebut juga digunakan untuk mengobati berbagai penyakit yakni lever, kanker dan tekanan darah tinggi (Harmanto,Ning; 2005).

Tujuan Penelitian ini adalah Untuk mengetahui pengaruh pemberian air rebusan mahkota dewa terhadap kadar asam urat dalam darah pada wanita menopause.

\section{Metode Penelitian}

Desain yang digunakan dalam penelitian ini adalah penelitian praeksperimental dengan pendekatan Pre Test- Post Test Design. Peneliti memberi perlakuan yaitu memberikan air rebusan mahkota dewa pada wanita menopause. Pengamatan terhadap dampak dari perlakuan atau tujuan penelitian dilakukan setelah perlakuan atau intervensi diberikan pada subyek penelitian.

Populasi yang digunakan adalah wanita menopause yang menderita asam urat di Kelurahan Kebonsari Kecamatan Sukun Kota Malang sebanyak 24 responden. Teknik 
sampling dalam penelitian ini menggunakan total sampling yaitu semua populasi yang ada diambil sebagai sampel yaitu sejumlah 24 responden dengan kriteria inklusi: Wanita menopause dengan kadar asam urat di atas 6 $\mathrm{mg} / \mathrm{dl}$ dan bersedia menjadi responden. Sedangkan kriteria eksklusi: Wanita menopause yang sedang mengkonsumsi obat-obatan yang berpengaruh pada kadar asam urat. Lokasi penelitian ini di RW 01 Kelurahan Kebonsari Kecamatan Sukun Kota Malang. Waktu penelitian dilakukan pada periode bulan Juli 2015 .

Pada proses pengumpulan data sebelum dilakuakn perlakuan (pre test) terlebih dahulu dikalukan mengukur kadar asam urat darah menggunakan Blood Uric Acid Meter dan mencatat dalam lembar observasi. Perlakuan diberikan dengan kunjungan rumah responden 1 kali sehari selama 7 hari dengan bantuan enumerator sejumlah 3 orang yang sebelumnya telah diberikan penjelasan mengenai tugasnya yaitu mendistribusikan air rebusan mahkota dewa ke rumah responden yang sudah dibagi sebelumnya dan memantau responden selama mengkonsumsi air rebusan mahkota dewa tersebut sampai habis. Air rebusan mahkota dewa yang diberikan dibuat oleh peneliti dan diantarkan ke rumah responden dimulai pada pukul 16.00 WIB. Pada hari ke-8, peneliti kembali melakukan pengukuran kadar asam urat darah pada seluruh responden (post test) menggunakan Blood Uric Acid Meter dan mencatat hasilnya dalam lembar observasi. Data yang diperoleh dari lembar observasi dimasukkan ke dalam mastersheet untuk dilakukan pengolahan data. Uji statistik yang digunakan dalam penelitian ini adalah Wilcoxon Signed Rank Test.

\section{Hasil Penelitian}

\subsection{Data Umum}

Usia Ibu

Tabel 1. Distribusi Frekuensi Responden Berdasarkan Umur

\begin{tabular}{lcc}
\hline \multicolumn{1}{c}{ Umur } & Frekuensi (f) & Persentase (\%) \\
\hline 48 th-55 th & 11 & 45,8 \\
56 th-60 th & 6 & 25 \\
61 th-65 th & 3 & 12,5 \\
$>$ 65 th & 4 & 16,7 \\
\hline Total & $\mathbf{2 4}$ & $\mathbf{1 0 0}$ \\
\hline
\end{tabular}

Bedasarkan tabel diketahui bahwa 45,8\% (11 responden) berada pada rentang usia 4855 tahun.

\subsection{Data Khusus}

Tabel 2. Tabel Rata-rata Kadar Asam Urat Sebelum dan Setelah Diberi Air Rebusan Mahkota Dewa

\begin{tabular}{lc}
\hline $\begin{array}{c}\text { Kadar Asam } \\
\text { Urat }\end{array}$ & $\begin{array}{c}\text { Rata - Rata Kadar } \\
\text { Asam Urat } \\
\text { (mg/dL) }\end{array}$ \\
\hline $\begin{array}{l}\text { Sebelum } \\
\text { pemberian air } \\
\text { rebusan } \\
\text { mahkota dewa }\end{array}$ & 7,2 \\
\hline $\begin{array}{l}\text { Setelah } \\
\text { pemberian air } \\
\text { rebusan } \\
\text { mahkota dewa }\end{array}$ & 6,2 \\
\hline
\end{tabular}

Berdasarkan data tabel 2. didapatkan ratarata kadar asam urat darah sebelum adalah $7,2 \mathrm{mg} / \mathrm{dl}$ dan rata-rata kadar asam urat darah sesudah adalah $6,2 \mathrm{mg} / \mathrm{dl}$.

Tabel 3. Distribusi Frekuensi Responden Berdasarkan Perubahan Kadar Asam Urat Darah Setelah Diberi Air Rebusan Mahkota Dewa

\begin{tabular}{lcc}
\hline Kriteria & $\begin{array}{c}\text { Frekuensi } \\
\text { (f) }\end{array}$ & $\begin{array}{c}\text { Persentase } \\
(\boldsymbol{\%})\end{array}$ \\
\hline Turun & 21 & 87,5 \\
Tetap & 3 & 12,5 \\
Naik & 0 & 0 \\
\hline Total & $\mathbf{2 4}$ & $\mathbf{1 0 0}$ \\
\hline
\end{tabular}

Berdasarkan data tabel 3. dari keseluruhan 24 responden diperoleh 87,5\% (21 responden) mengalami penurunan kadar asam urat.

\subsection{Hasil Uji Hipotesis}

Uji statistik yang bertujuan untuk mengetahui pengaruh pemberian air rebusan mahkota dewa terhadap kadar asam urat darah pada wanita menopause didapatkan nilai Z: 4,020 dengan $\rho$ value : 0,001 maka 
$\mathrm{H}_{0}$ ditolak yang artinya ada pengaruh pemberian air rebusan mahkota dewa terhadap kadar asam urat pada wanita menopause

\section{Pembahasan}

Asam urat adalah asam yang berbentuk kristal-kristal yang merupakan hasil akhir dari metabolisme purin, yaitu salah satu komponen asam nukleat yang terdapat pada inti sel-sel tubuh dan secara alamaiah terdapat dalam tubuh. (Saraswati, 2009). Menurut Dr. Suryo Wibowo, MKK, SpOk, Pada wanita usia reproduksi yang masih mempunyai hormon estrogen kadar asam urat dalam darah terkontrol. Sehingga usia wanita mempengaruhi kadar asam urat dalam darah. Pada hasil penelitian yang telah dilakukan, didapatkan bahwa $45,8 \%$ berada dalam rentang usia 48-55 tahun. Jadi, sampel berada pada usia fase pramenopause. Sesuai dengan teori bahwa wanita pada usia reproduksi masih mempunyai hormon estrogen yang berpengaruh dalam pengeluaran asam urat. Sehingga pada perempuan kadar asam urat tidak meningkat sampai setelah menopause.

Menurut penelitian yang telah dilakukan, yaitu sebelum pemberian air rebusan mahkota dewa didapatkan bahwa seluruh responden (24 responden) memiliki kadar asam urat di atas normal. Menurut Michael A. Carter (2006), Hormon estrogen akan membantu meningkatkan pengeluaran asam urat dalam ginjal dengan mengurangi jumlah reabsorbsi asam uratnya. Normalnya 98\% asam urat yang difiltrasi direabsorbsi dan $2 \%$ sisanya membentuk sekitar $20 \%$ jumlah yang diekskresikan. Sisanya $80 \%$ berasal dari sekresi tubulus. Sehingga dengan bantuan hormon estrogen, jumlah asam urat yang diekskresikan akan meningkat daripada jumlah asam urat yang direabsorbsi. Tetapi karena setelah menopause, hormon estrogen tidak lagi diproduksi maka kadar asam urat akan meningkat.

Setelah dilakukan pemberian air rebusan mahkota dewa sebanyak $1 \mathrm{x}$ sehari selama 7 hari berturut-turut, didapatkan hasil bahwa 21 responden mengalami penurunan kadar asam urat darah. Hasil tersebut menunjukkan bahwa pemberian air rebusan mahkota dewa dapat menurunkan kadar asam urat darah pada wanita menopause.

Kandungan kimia dalam buah mahkota dewa terdiri atas alkaloid, tanin, flavonoid, saponin, polifenol. Keefektifan mahkota dewa untuk mengobati asam urat diduga didasarkan pada kandungan flavonoidnya. Menurut Arini (2003), ekstrak etanol 70\% daging buah mahkota dewa mempunyai kadar relatif flavonoid yang paling besar $(45,734 \mu \mathrm{g} / \mathrm{mg})$. Kemampuan senyawa tersebut dalam menurunkan asam urat adalah dengan mekanisme hambatan terhadap aktivitas xantin oksidase pada basa purin sehingga akan menurunkan produksi asam urat.

Menurut Wibowo (2010), manusia mengubah nukleosida purin utama, adenosin dan guanin menjadi asam urat. Pertama-tama adenosin mengalami deaminasi menjadi inosin oleh enzim adenosin deaminase. Fosforolisis ikatan N-glikosidat inosin dan guanosin, yang dikatalisis oleh enzim nukleosida purin fosforilase, akan melepaskan senyawa ribosa 1 - fosfat dan basa purin. Selanjutnya hipoxantin dan guanin membentuk xantin oleh reaksi yang masing-masing dikatalisis oleh enzim oksidase dan guanase. Kemudian xantin teroksidasi menjadi asam urat dalam reaksi kedua yang dikatalisis oleh enzim xantin oksidase. Jadi dengan adanya kandungan flavonoid pada buah mahkota dewa yang memiliki mekanisme hambatan pada aktivitas xantin oksidase, maka akan menurunkan pembentukan asam urat sehingga konsentrasi asam ini dalam darah dan jaringan menurun.

\section{Kesimpulan dan Saran}

\subsection{Kesimpulan}

Ada pengaruh yang signifikan (bermakna) pada pemberian air rebusan mahkota dewa terhadap penurunan kadar asam urat darah pada wanita menopause.

\subsection{Saran}

Wanita menopause yang mengalami penyakit asam urat hendaknya memanfaatkan tanaman-tanaman herba seperti mahkota dewa untuk digunakan sebagai alternatif dalam menurunkan kadar asam urat. Namun penggunaan tanaman tradisional tersebut harus sesuai dengan 
aturan yang telah ada terutama tentang dosis dan cara penggunaan termasuk cara pengolahan.

\section{DAFTAR PUSTAKA}

Arini S, Nurmawan D, Alfiani F, Hertiani T. 2003. Daya Antioksidan dan Kadar Flavonoid Hasil Ekstraksi Etanolair Daging Buah Mahkota Dewa (Phaleria macrocarpa (Scheff.) Boerl.). Buletin Penalaran Mahasiswa UGM

Baziat, Ali. 2003. Menopause dan Andropause. Jakarta. YBPSP.

Dewani. 2006. 33 Ramuan Penakluk Asam Urat. Jakarta: Agro Media Pustaka

Dini, Kasdu. 2002. Kiat Sehat dan Bahagia di Usia Menopause. Jakarta. Puspa Suara.

Harmanto, Ning. 2005. Menggempur Asam Urat dan Rematik dengan Mahkota Dewa. Jakarta: Agro Media Pustaka

Harmanto, Ning. 2005. Menaklukkan Penyakit Bersama mahkota Dewa. Jakarta. Agromedia Pustaka,

Hidayat. 2007. Metode Penelitian Kebidanan dan Tehnik Analisis Data. Jakarta: Salemba Medika

Jones-Derek Llewelyn. 2001. Dasar-dasar Obstetri dan Ginekologi. Jakarta. Hipokratis.

Junaedi, dr.Iskandar.2008.Rematik dan Asam Urat.Jakarta:PT.Buana Ilmu Populer.

Kertia, Nyoman. 2009. Asam Urat Benarkah Hanya Menyerang Laki -Laki. Yogyakarta: Bentang Pustaka.

Muhammad, As'adi. 2010. Waspadai Asam Urat. Yogyakarta: Diva Press.

Murray, Robert K dkk. 2003. Biokimia Harper. Jakarta: EGC

Saraswati, Sylvia. 2009. Diet Sehat: untuk Penyakit Asam Urat, Diabetes, Hipertensi, dan Stroke. Yogyakarta: A+Plus Books.

Spencer, Rebecca Fox dan Pam Brown. 2006. Menopause. Jakarta: Erlangga.

Tagliaferri, Mary. 2006. The New Menopause Book: Ihwal yang Perlu Anda Ketahui Menopause. Jakarta. PT. Indeks Kelompok Gramedia.
Tersono, Lukas. 2008. Tanaman Obat dan Jus untuk Mengatasi Penyakit Jantung, Hipertensi, Kolesterol, dan Stroke. Jakarta: Agro Media Pustaka.

Varney, Helen et al. 2006. Buku Ajar Asuhan Kebidanan Volume 1. Jakarta: EGC

Wibowo, Suryo. 2009. 100 Questons \& Answers Asam Urat. Jakarta : PT Elex Media Komputindo

Wijayakusuma, Hembing. 2006. Atasi Rematik dan Asam Urat Ala Hembing. Jakarta : Puspa Swara.

Winarto, W.P. 2005. Mahkota Dewa: Budidaya \& Pemanfaatan untuk Obat. Jakarta: Penebar Swadaya

Yatim, Faisal. 2001. Haid Tidak Lancar dan Menopause. Jakarta. Pustaka Populer Obor. 